\title{
The comparison between the medical and the surgical management of chronic anal fissures
}

\author{
Navneet Mishra ${ }^{1}$, Kamal Kishore Parmar ${ }^{1}$, Tanweerul Huda ${ }^{1 *}$ \\ ${ }^{1}$ DEPARTMENT OF GENERAL SURGERY, LN MEDICAL COLLEGE, BHOPAL, M.P, INDIA
}

\begin{abstract}
Introduction. Anal fissures can be defined as a tear or a break in the anoderm. Acute fissures do not exceed a 6 week-duration and can be seen as a simple tear in the anoderm along with edema, whereas chronic fissures are longer than 6 weeks. Aim. To compare the efficacy of the medical and surgical options for the treatment of chronic anal fissures and to recommend the appropriate option in terms of their symptomatic relief, healing of fissures and long-term effectiveness. Materials \& Methods. A prospective observational study was conducted for a period of 2 years, that is, from October 2018 to October 2020, including a follow-up period of 2 months. A total of 72 patients with chronic anal fissures were included in the study and randomized into two groups, represented by the medical management group and the surgical management group (Lateral Internal Sphincterotomy (LIS)). Results. In the case of the 36 patients with CAF (chronic anal fissure) who underwent surgical management, all $36(100 \%)$ patients had optimal healing of the fissure at 6 weeks. In the case of the 36 patients with CAF who underwent medical management, only $32(89 \%)$ patients had optimal healing of the fissure at 6 weeks, whereas 4 patients failed to heal even after 2 months. Conclusions. Surgical management is the preferable method for chronic anal fissures in comparison to medical management. But the medical management has a role in acting as a bridge to surgical management in patients who are not fit for surgery or do not perceive surgery as an option at the time.
\end{abstract}

Category: Original Research Paper

Received: January 17, 2021

Accepted: March 19, 2021

Published: May 10, 2021

\section{Keywords:}

chronic anal fissures, medical management, lateral sphincterotomy, bleeding per rectum.

*Corresponding author:

Tanweerul Huda,

Department of General Surgery, LN Medical College, Bhopal, India. E-mail: tanweer11@gmail.com

E-mail: tanweer11@gmail.com

\section{Introduction}

Anal fissures are defined as a tear or a break in the anoderm. Fissures can occur at any age, more commonly in middle aged people, predominantly in females. They are found mostly in the posterior $(90 \%)$ or anterior midline (10\%) and less than $1 \%$ in uncommon locations [1]. Fissures occurring in uncommon sites are usually due to instrumentations or diseases such as Crohn's disease, syphilis, tuberculosis, human immunodeficiency virus (HIV)/ acquired immunodeficiency syndrome (AIDS), or anal carcinoma. The most prevalent cause of an anal fissure is trauma from either the hard stool passage or prolonged diarrhea $[1,2]$. Acute fissures have been defined as having symptoms shorter than a 6 week-duration, whereas chronic fissures have symptoms lasting more than 6 weeks. Acute fissures are seen as a simple tear in the anoderm along with edema, whereas chronic fissures are accompanied by additional fibrosis, hypertrophied anal papilla, and sentinel tags [2,3].

\section{Materials and Methods}

A prospective observational study was conducted for a period of 2 years, i.e. from October 2018 to October 2020, including a follow-up period of 2 months. A total number of 72 patients with chronic anal fissures were included in the study.

\section{Inclusion criteria}

- Patients with chronic anal fissures

- Age ranging from 16 to 75 years

- Both males and females

\section{Exclusion criteria}

- Patients with acute anal fissures

- Age younger than 16 years or older than 75 years 
- Pregnant females

- Patients diagnosed with inflammatory bowel disease, colon carcinoma, anal carcinoma

- Patients under treatment for ischemic heart diseases

The clinical details and the history of symptoms such as pain during defecation, constipation, bleeding per rectum, any discharge, and soiling along with examination findings were recorded on the standardized proforma. The patients were randomized into two groups, represented by the medical management group and the surgical management group (Lateral Internal Sphincterotomy). The medical management group were given sitz baths, nifedipine local applications along with calcium channel blockers. Lateral internal sphincterotomy was performed for the surgical group.

All cases underwent follow-ups for a period of 2 months, following the set protocol.

\section{Results}

We included 72 patients with chronic anal fissures, out of which $27(37.5 \%)$ were males, and 45 (62.5\%) were females. Therefore, the maximum incidence in our study, according to gender, was among females (Table 1).

Table 1. Distribution of Patients According to Gender in The Study Population

\begin{tabular}{|l|c|c|}
\hline Sex & Frequency & Percentage \\
\hline Female & 45 & $62.5 \%$ \\
\hline Male & 27 & $37.5 \%$ \\
\hline Total & 72 & $100 \%$ \\
\hline
\end{tabular}

Out of the 72 patients, the maximum number of patients, i.e. 20 (28\%), were included in the age group 3645 years and the least number of patients 1 (1\%) was included in the age group 66-75 years. A number of 16 (22\%) patients was included in the 26-35-year age group, $19(27 \%)$ patients in the age group of $46-55$ years, followed by $8(11 \%)$ patients in the group of $16-25$ years and 8 (11\%) patients in the 56-65-year age group (Table 2).

Out of the 72 patients with chronic anal fissures included in our study, $68(94 \%)$ patients presented especially with complaints of pain, whereas $4(6 \%)$ patients did not present with any pain at all (Table 3). Out of the 72 patients with chronic anal fissures, $40(56 \%)$ patients complained of bleeding per rectum, whereas in $32(44 \%)$ patients of the study population, bleeding per rectum was absent (Table 4). Out of the 72 patients, the incidence of constipation was reported in 67 (93\%) patients, whereas $5(7 \%)$ patients did not have any history of constipation (Table 5).
Table 2. Distribution of Patients According to Age in Study Population

\begin{tabular}{|l|c|l|}
\hline Age (Years) & Number of Patients & Percentage \\
\hline $\mathbf{1 6 - 2 5}$ & 8 & $11 \%$ \\
\hline $\mathbf{2 6 - 3 5}$ & 16 & $22 \%$ \\
\hline $\mathbf{3 6 - 4 5}$ & 20 & $28 \%$ \\
\hline $\mathbf{4 6 - 5 5}$ & 19 & $27 \%$ \\
\hline $\mathbf{5 6 - 6 5}$ & 8 & $11 \%$ \\
\hline $\mathbf{6 6 - 7 5}$ & 1 & $1 \%$ \\
\hline Total & 72 & $100 \%$ \\
\hline
\end{tabular}

Table 3. Distribution of Chief Complaint of Pain in The Study Population

\begin{tabular}{|l|c|c|}
\hline Pain & Frequency & Percentage \\
\hline Present & 68 & $94 \%$ \\
\hline Absent & 4 & $6 \%$ \\
\hline Total & 72 & $100 \%$ \\
\hline
\end{tabular}

Table 4. Distribution of Complaint of Bleeding Per Rectum in The Study Population

\begin{tabular}{|l|c|c|}
\hline Bleeding (P/R) & Frequency & Percentage \\
\hline Present & 40 & $56 \%$ \\
\hline Absent & 32 & $44 \%$ \\
\hline Total & 72 & $100 \%$ \\
\hline
\end{tabular}

Table 5. Distribution of Associated Constipation in The Study Population.

\begin{tabular}{|l|c|c|} 
Constipation & Frequency & Percentage \\
\hline Present & 67 & $93 \%$ \\
\hline Absent & 5 & $7 \%$ \\
\hline Total & 72 & $100 \%$ \\
\hline
\end{tabular}


The study population (72 patients) was divided into the medical and surgical (lateral internal sphincterotomy) group by randomization leading to $50 \%$ (36) cases in lateral internal sphincterotomy and 50\% (36) cases in the medical group. The study population of 72 patients thus were either operated on for chronic anal fissure (CAF) through lateral internal sphincterotomy, or underwent medical management, patients being evaluated for pain on the 3rd post-intervention day. A number of $27(75 \%)$ patients in the medical management group experienced pain, and only $5(14 \%)$ patients in the surgical management group experienced pain (Table 6).

Table 6. Distribution of Pain after Medical and Surgical management on 3rd Day in the study population

\begin{tabular}{|l|c|c|c|c|}
\hline $\begin{array}{l}\text { Type of } \\
\text { intervention }\end{array}$ & Present & Absent & Total & Percentage \\
\hline Medical & 27 & 09 & 36 & $75 \%$ \\
\hline Surgical & 05 & 31 & 36 & $14 \%$ \\
\hline Total & & & 72 & \\
\hline
\end{tabular}

Out of the study population of 72 patients who were operated on for (CAF) through lateral internal sphincterotomy or who underwent medical management were evaluated for pain on the 7 th post-intervention day. A number of $9(25 \%)$ patients in the medical management group were in pain at that time, whereas no patient in the surgical group felt any pain at all (Table 7).

Table 7. Distribution of Pain After Medical and Surgical Management On 7th Day in The Study Population.

\begin{tabular}{|l|c|c|c|c|}
\hline $\begin{array}{l}\text { Type of } \\
\text { intervention }\end{array}$ & Present & Absent & Total & Percentage \\
\hline Medical & 09 & 27 & 36 & $25 \%$ \\
\hline Surgical & 0 & 36 & 36 & $0 \%$ \\
\hline Total & & & 72 & \\
\hline
\end{tabular}

Out of the 36 patients with CAF who underwent medical management, no patient had been adequately healed within 1 week. A number of $4(11 \%)$ patients had adequate healing at 2 weeks, $8(22 \%)$ patients had adequate healing at 4 weeks, followed by $20(56 \%)$ patients who had optimal healing of the fissure at 6 weeks, whereas 4 patients failed to heal even after 2 months (Table 8). Out of the 36 patients with CAF who underwent surgical management, 5 (14\%) patients had adequate healing at 1 week, $16(44 \%)$ patients had adequate healing at 2 weeks, $10(28 \%)$ patients had adequate healing at 4 weeks, followed by $5(14 \%)$ patients who had optimal healing of the fissure at 6 weeks. Thus, all $36(100 \%)$ patients had optimal healing of the fissure within 6 weeks (Table 9).
Table 8. Distribution of optimal healing of fissure after medical management in the study population.

\begin{tabular}{|l|c|c|c|}
\hline $\begin{array}{l}\text { Follow } \\
\text { up }\end{array}$ & Inadequate & Adequate & $\begin{array}{c}\text { Percentage of } \\
\text { healing }\end{array}$ \\
\hline 1 week & 36 & 0 & $0 \%$ \\
\hline $\mathbf{2}$ weeks & 32 & 4 & $11 \%$ \\
\hline $\mathbf{4}$ weeks & 24 & 8 & $22 \%$ \\
\hline 6 weeks & 4 & 20 & $56 \%$ \\
\hline 2 months & 4 & 20 & $56 \%$ \\
\hline Total & & & $89 \%$ \\
\hline
\end{tabular}

Table 9. Distribution of Optimal Healing of Fissure After Surgical Management in The Study Population

\begin{tabular}{|c|c|c|c|}
\hline Follow up & Inadequate & Adequate & $\begin{array}{c}\text { Percentage of } \\
\text { Healing }\end{array}$ \\
\hline $\mathbf{1}$ week & 31 & 5 & $14 \%$ \\
\hline $\mathbf{2}$ weeks & 15 & 16 & $44 \%$ \\
\hline $\mathbf{4}$ weeks & 05 & 10 & $28 \%$ \\
\hline $\mathbf{6}$ weeks & 0 & 5 & $14 \%$ \\
\hline months & 0 & 0 & $100 \%$ \\
\hline Total & & 36 & $100 \%$ \\
\hline
\end{tabular}

Out of the 36 patients with CAF who underwent surgical management, $11(31 \%)$ patients had a postoperative hospital stay for 1 day, $20(56 \%)$ patients had a postoperative hospital stay for 2 days, $2(5 \%)$ patients had a postoperative hospital stay for 3 days and $2(5 \%)$ had a postoperative hospital stay for 4 days, while only $1(3 \%)$ patient stayed in the hospital for 5 days (Table 10).

Table 10: Mean Postoperative Hospital Stay in Surgical Group

\begin{tabular}{|c|c|c|}
\hline Duration (Days) & No. of Patients & Percentage \\
\hline 1 & 11 & $31 \%$ \\
\hline 2 & 20 & $56 \%$ \\
\hline 3 & 2 & $5 \%$ \\
\hline 4 & 2 & $5 \%$ \\
\hline 5 & 1 & $3 \%$ \\
\hline Total & 36 & $100 \%$ \\
\hline
\end{tabular}




\section{Discussions}

Over $90 \%$ of all acute anal fissures will heal either spontaneously or if some simple measures are taken. A diet rich in fiber along with an increased fluid intake is recommended. Laxatives are used as a stool softener, whereas warm sitz baths provide pain relief. Topical preparations of hydrocortisone and local anesthetics have also been helpful [3].

A small number of chronic fissures heal without any intervention, but the vast majority do not [4]. Medical therapy is employed as the first-line treatment for chronic fissures; however, its failure requires surgical management.

There are various surgical options for chronic anal fissures such as an anal stretch, internal sphincterotomy, fissurectomy, or more recently, the mucosal advancement flaps [5]. Anal stretch is an obsolete procedure causing a permanent disruption of the sphincters. Around 39\% of the patients have flatus incontinence and soiling, whereas up to $16 \%$ have fecal incontinence. The recurrence rates of this procedure can be as high as $56.5 \%$ of all cases [6].

Lateral internal sphincterotomy (LIS) is the most widely accepted surgical means performed worldwide using either a closed or an open technique. Studies have revealed that the results of both techniques are similar [7]. The lateral sphincterotomy's optimal length is undecided, but most accept that the incision length should be up to the length of the fissure. Varying levels of incontinence are seen in approximately $35 \%$ of the patients with LIS, which is more frequently found in women [8].

Lund et al. (2006) suggested that after the diagnosis of anal fissure, the first-line treatment with topical nitrates or calcium channel blockers should be started along with increased dietary fibers or addition of bulking agents. Unhealed symptomatic patients were referred to for secondary care, which included surgery and botulinum toxin [9].

In their study, Collins et al. (2007) concluded that the treatment for chronic anal fissures is aimed at reducing the spasm of anal sphincters and increasing blood supply to these ischemic ulcers. Medical therapy with topical nitrates seems to be beneficial. Surgery should be reserved to those failing nonsurgical treatment, patients should probably be given LIS in most cases [10].

Mariusz H. Madalinski (2011) conducted a study entitled "Identifying the best therapy for anal fissure". He concluded that chemical sphincterotomy should be considered for anal fissures, keeping in mind the financial impact [11].

In their study entitled "Delayed fecal incontinence following surgery for anal fissure", Avi Levin et al. (2011) assessed whether surgical treatment of anal fissures contributed to the development of delayed anal incontinence. They concluded that incontinence may be associated with other co-factors accumulating overtime or more likely, anal fissure surgery may accelerate the physiologic age-related weakening of the anal sphincters [12].

Altomare et al. (2011) carried out a review that was aimed at identifying the best treatment option for anal fissures. They concluded that conservative therapy rarely provided a cure, and that the medical treatment with diltiazem, and nifedipine or glyceryl trinitrate, had a considerable curative rate ranging from $50 \%$ to $90 \%$. The amount of $0.4 \%$ glyceryl trinitrate in a standardized fashion had the best results, whereas botulinum toxin resulted in inconsistent outcomes. They advocated nonresponding patients as candidates for lateral internal sphincterotomy [13].

Leo Francis Tauro et al. (2011) found LIS to be better than PIS (Posterior Internal Sphincterotomy). Lateral sphincterotomy should be performed in the case of patients who do not respond to chemical sphincterotomy or medical therapy. For patients who reject surgery and choose medical care instead, GTN therapy is a successful alternative mode of treatment [14].

Qureshi et al. (2008) carried out a comparative study between the Surgical Versus Nonsurgical Treatment of Chronic Anal Fissures. They concluded that chemical sphincterotomy with topical nifedipine ointment is quite effective, but LIS is a safe and excellent procedure with a high satisfaction rate among the patients [15].

In their article entitled "Anal fissure", Karen N. Zaghiyan et al. (2011) concluded that anal fissures can be treated conservatively, but pharmacologic management is also judicious with fewer side effects and good healing. LIS is the gold standard for the anal fissure management. Open or closed techniques have similar healing and complication rates. The anal stretch should no longer be performed [16].

In their study, G. Rosa et al. (2005) concluded that LIS is effective for the treatment of anal fissures, but it can cause anal incontinence. The internal sphincter was divided in terms of anal manometry. In mild cases of hypertonia, $20 \%$ of the internal sphincter was divided; in moderate hypertonia, $40 \%$ was divided, and in cases of severe hypertonia, $60 \%$ was divided [17].

Sarabjit Singh et al (2011) performed an Evaluation of the Left Lateral Internal Sphincterotomy (LLIS) for the Surgical Management of Chronic Anal Fissures. They concluded that LLIS is an excellent surgical procedure for chronic anal fissures not responding to conservative means [18].

Abdul-Wahid M. Salih (2016) conducted a study on Open Lateral internal sphincterotomy in terms of recurrence rate, complications, and patient's satisfaction. They concluded that lateral internal sphincterotomy is the 
procedure of choice for chronic anal fissures for its symptomatic relief and healing rates along with a low complication rate, and insignificant recurrence rates [19].

In their Retrospective study, Gregg M. Baranski et al. (2016) reviewed 253 patients with chronic fissures undergoing open or closed LIS for anal fissure over a period of 5 years. Compared to the closed technique, the open technique had an increased incidence of wound infection, return to the operating room, delayed healing, but fissure healing was comparable in both methods [20].

\section{Conclusions}

Based on the findings resulting from our study, we can conclude that surgical management provides a better outcome in terms of healing and pain control in cases of both acute and chronic anal fissures. The surgical management provides rapid pain relief, thereby leading to an early resumption of work as compared to medical management, thus, leading to a decreased financial burden for the working population. The medical management is suitable for the primary management of the patients for whom surgery is not feasible due to contraindications or due to a lack of the patient's consent. Thus, medical management can be used as a bridge to the surgical procedure in cases where surgery is not feasible at that time and as an adjunct to the surgical procedure.

\section{Conflict of interest disclosure}

There are no known conflicts of interest in the publication of this article. The manuscript was read and approved by all authors.

\section{Compliance with ethical standards}

Any aspect of the work covered in this manuscript has been conducted with the ethical approval of all relevant bodies and that such approvals are acknowledged within the manuscript.

\section{References}

1. Sileri P, Mele A, Stolfi VM, Grande M, Sica G, Gentileschi P, Di Carlo S, Gaspari AL. Medical and surgical treatment of chronic anal fissure: a prospective study. J Gastrointest Surg. 2007;11(11):1541-8. doi: 10.1007/s11605-007-0255-3

2. Zeitoun JD, Blanchard P, Fathallah N, Benfredj P, Lemarchand N, de Parades V. Long-term Outcome of a Fissurectomy: A Prospective Single-Arm Study of 50 Operations out of 349 Initial Patients. Ann Coloproctol. 2018;34(2):83-87. doi: 10.3393/ac.2017.06.12

3. Motie MR, Hashemi P. Chronic Anal Fissure: A Comparative Study of Medical Treatment Versus
Surgical Sphincterotomy. Acta Med Iran. 2016;54(7): 437-40. PMID: 27424014.

4. Ebinger SM, Hardt J, Warschkow R, Schmied BM, Herold A, Post S, Marti L. Operative and medical treatment of chronic anal fissures-a review and network meta-analysis of randomized controlled trials. $J$ Gastroenterol. 2017 Jun;52(6):663-676. doi: 10.1007/s00535-017-1335-0

5. Olfat El-Sibai, Ahmed Sabri, Ahmed E Ahmed Omara. A comparative study between lateral internal sphincterotomy (an alternative approach) and fissurectomy in the surgical management of chronic idiopathic anal fissure. Menoufia Medical Journal. 2017;30(2):383-7. doi: 10.4103/1110-2098.215440

6. Acar T, Acar N, Güngör F, Kamer E, Genç H, Atahan K, Dilek ON, Haciyanlı M. Comparative efficacy of medical treatment versus surgical sphincterotomy in the treatment of chronic anal fissure. Niger J Clin Pract. 2020 Apr;23(4):539-544. doi: 10.4103/njcp.njcp_383_19

7. Arroyo A, Montes E, Calderón T, Blesa I, Elía M, Salgado G, García-Armengol J, de-la-Portilla F. Treatment algorithm for anal fissure. Consensus document of the Spanish Association of Coloproctology and the Coloproctology Division of the Spanish Association of Surgeons. Cir Esp. 2018;96(5):260-267. English, Spanish. doi: 10.1016/j.ciresp.2018.02.007

8. Acheson AG, Scholefield JH. Anal fissure: the changing management of a surgical condition. Langenbecks Arch Surg. 2005;390(1):1-7. doi: 10.1007/s00423-003-0430-2

9. Lund JN, Nyström PO, Coremans G, Herold A, Karaitianos I, Spyrou M, Schouten WR, Sebastian AA, Pescatori M. An evidence-based treatment algorithm for anal fissure. Tech Coloproctol. 2006;10(3):177-80. doi: 10.1007/s10151-006-0276-z

10. Collins EE, Lund JN. A review of chronic anal fissure management. Tech Coloproctol. 2007;11(3):209-23. doi: 10.1007/s10151-007-0355-9

11. Madalinski MH. Identifying the best therapy for chronic anal fissure. World J Gastrointest Pharmacol Ther. 2011;2(2):9-16. doi: 10.4292/wjgpt.v2.i2.9

12. Levin A, Cohen MJ, Mindrul V, Lysy J. Delayed fecal incontinence following surgery for anal fissure. Int $J$ Colorectal Dis. 2011;26(12):1595-9. doi: 10.1007/s00384-011-1284-7

13. Altomare DF, Binda GA, Canuti S, Landolfi V, Trompetto M, Villani RD. The management of patients with primary chronic anal fissure: a position paper. Tech Coloproctol. 2011; 15(2): 135-41. doi: 10.1007/s10151-011-0683-7 
14. Tauro LF, Shindhe VV, Aithala PS, Martis JJ, Shenoy HD. Comparative study of glyceryl trinitrate ointment versus surgical management of chronic anal fissure. Indian J Surg. 2011;73(4):268-77. doi: 10.1007/s12262-011-0239-0

15. Qureshi U, Khan J, Malik A, Khan M. Surgical Versus Nonsurgical Treatment of Chronic Anal Fissure: Our Local Experience. Ann Pak Inst Med Sci. 2008;4(4):193-197.

16. Zaghiyan KN, Fleshner P. Anal fissure. Clin Colon Rectal Surg. 2011;24(1):22-30. doi: 10.1055/s-00311272820

17. Rosa G, Lolli P, Piccinelli D, Mazzola F, Zugni C, Ballarin A, Bonomo S. Calibrated lateral internal sphincterotomy for chronic anal fissure. Tech
Coloproctol. 2005;9(2):127-31; discussion 131-2. doi: 10.1007/s10151-005-0210-9

18. Singh S, Tayal A, Singh H, Kaur V. Surgical Management of Chronic Anal Fissure: Evaluation of Left Lateral Internal Sphincterotomy (LLIS). JIMSA. 2011;24(2):95-96.

19. Salih AWM. Anal fissures: Open lateral internal sphincterotomy results. J Epidemiol Res. 2016;2(1):8790. doi: 10.5430/jer.v2n1p87

20. Yushuva A, Baranski G, Park J. Comparison of Wound Complications in Open vs Closed Lateral Internal Sphincterotomy for Anal Fissure. Poster presented at: American Society of Colon and Rectal Surgeons, Los Angeles, CA. 2016. https://scholarlyworks.lvhn.org/ cgi/viewcontent.cgi?article $=1829 \&$ context=surgery 